\title{
Corrosion Behavior of 2205 DSS Base Metal and ER 2209 Weld Metal in a Deposited Ash/Water Suspension
}

\author{
Fang Ge, Xin Huang, Yi Zhang, Yanfang Song, Xinjing Meng*, Honghua Ge*, Yuzeng Zhao* \\ Shanghai Engineering Research Center of Energy-Saving in Heat Exchange Systems, Shanghai Key \\ Laboratory of Materials Protection and Advanced Materials in Electric Power, Shanghai University of \\ Electric Power, Shanghai 200090, China \\ *E-mail: mengxinjing@ shiep.edu.cn, gehonghua@ shiep.edu.cn, zhaoyuzeng@ shiep.edu.cn
}

doi: $10.20964 / 2021.07 .35$

Received: 1 April 2021 / Accepted: 6 May 2021 / Published: 31 May 2021

\begin{abstract}
The corrosion behavior of 2205 duplex stainless steel (DSS) base metal (BM) and ER2209 weld metal (WM) in an ash/water suspension composed of deposited ash on the flue gas side of a low-temperature heat exchanger in a waste-to-energy plant and water was studied by polarization curve analysis, electrochemical impedance spectroscopy (EIS), localized electrochemical measurements, microscopic surface morphology observation, and metallographic analysis. The results showed that the corrosion resistance of both the BM and the WM decreased with the increase in immersion time. After $4 \mathrm{~h}$ of immersion, active sites where the current density increased suddenly appeared on the surface of the WM, and the surface roughness increased significantly, indicating the beginning of pitting on the WM surface. However, it took $8 \mathrm{~h}$ for the active sites to appear on the BM, and the pitting corrosion on the BM surface was obviously less than that of the WM surface under the same immersion time. The pitting corrosion resistance of the 2205 DSS BM was obviously better than that of the WM. According to the metallographic analysis results, the high proportion of dendritic ferrite in the metallographic structure of the WM may be the reason for its poor corrosion resistance.
\end{abstract}

Keywords: waste-to-energy plant; ash/water suspension; pitting; 2205 DSS base metal; ER2209 weld metal

\section{$\underline{\text { FULL TEXT }}$}

(C) 2021 The Authors. Published by ESG (www.electrochemsci.org). This article is an open access article distributed under the terms and conditions of the Creative Commons Attribution license (http://creativecommons.org/licenses/by/4.0/). 